\title{
MEDIASI MOTIVASI KERJA PADA HUBUNGAN KOMPENSASI DENGAN KOMITMEN ORGANISASIONAL
}

\author{
I Gede Riana ${ }^{1}$, Rai Mutiara Sari², I B Udayana Putra ${ }^{3}$ \\ ${ }^{1}$ Fakultas ekonomi dan Bisnis Universitas Udayana, gederiana@unud.ac.id \\ ${ }^{2}$ Magister manajemen FEB Unud, raimutiarasari@yahoo.co.id \\ ${ }^{3}$ Fakultas Ekonomi dan Bisnis Universitas Warmadewa, udayanap10@gmail.com
}

\begin{abstract}
ABSTRAK
Komitmen organisasional merupakan identifikasi, loyalitas, dan keterlibatan yang dinyatakan oleh karyawan, organisasi atau unit organisasi. Komitmen organisasional juga dipandang sebagai respon afektif pada organisasi secara menyeluruh, yang kemudian menunjukkan suatu respon afektif pada aspek khusus pekerjaan. Penelitian bertujuan untuk menganalisis peran mediasi motivasi kerja pada pengaruh kompensasi terhadap komitmen organisasional. Penelitian ini menggunakan teknik sampel jenuh dengan populasi sebanyak 146 karyawan dengan respon rate sebesar 73,79 \% yaitu 107 karyawan. Selanjutnya data yang telah terkumpul dianalisis menggunakan teknik analisis jalur. Hasil penelitian menunjukkan empat hipotesis yang diajukan dapat diterima. Kompensasi berpengaruh positif dan signifikan terhadap komitmen organisasional, kompensasi berpengaruh positif dan signifikan terhadap motivasi kerja, dan motivasi kerja berpengaruh positif dan signifikan terhadap komitmen organisasional. Penelitian ini juga menginformasikan bahwa motivasi kerja secara signifikan memediasi pengaruh kompensasi terhadap komitmen organisasional.
\end{abstract}

Kata Kunci: motivasi kerja, kompensasi, komitmen organisasional

\begin{abstract}
Organizational commitment is the identification, loyalty, and involvement expressed by employees, organizations or organizational units. Organizational commitment is also seen as an affective response to the organization as a whole, which then shows an affective response to specific aspects of the work. This research is to find out the mediating role of work motivation on the effect of compensation on organizational commitment. This study uses a saturated sample technique with a population of 146 employees with a response rate of $73.79 \%$, namely 107 employees. Furthermore the data collected has been analyzed using path analysis techniques. The results showed that four proposed hypotheses could be accepted. Compensation has positive and significant effect on organizational commitment, compensation has positive and significant effect on work motivation, and work motivation has a positive and significant effect on organizational commitment. However, this study also inform that work motivation significantly mediates the effect of compensation on organizational commitment.
\end{abstract}

Keywords: work motivation, compensation, organizational commitment 


\section{PENDAHULUAN}

Komitmen organisasional mulai mendapat perhatian serius di berbagai penelitian tentang perilaku organisasi karena berdampak signifikan terhadap sikap karyawan di tempat kerja dan kinerja. Alimohammadi dan Neyshabor (2013) menjelaskan komitmen organisasional merupakan permasalahan penting dalam perkembangan organisasi karena menjadi salah satu instrumen penting untuk menunjang peningkatan kinerja karyawan maupun organisasi. Komitmen organisasional sama seperti sikap kerja lainnya merupakan suatu sikap individu (Zayas-Ortiz et al., 2015) terhadap pekerjaan dan lingkungan organisasi. Namun demikian, komitmen organisasional sifatnya lebih umum dan merefleksikan respon afeksi individu terhadap organisasi secara keseluruhan dengan tugas khusus atau aspek-aspek tertentu dari pekerjaan. Secara informal komitmen organisasional merupakan ukuran kepercayaan dan kesetiaan yang dirasakan oleh karyawan terhadap organisasi pemberi kerja (Mogotsi et al., 2011), sehingga dapat dilihat sebagai penilaian positif terhadap lingkungan kerja (Testa, 2001). Oleh karena itu, komitmen lebih menekankan pada kepatuhan individu terhadap organisasi sebagai karyawan. Terdapat sejumlah faktor yang dapat meningkatkan komitmen karyawan terhadap organisasi, diantaranya adalah kompensasi dan motivasi.

Suparyadi (2015:271) menyatakan kompensasi merupakan keseluruhan imbalan yang diterima oleh karyawan sebagai penghargaan atas kontribusi yang diberikan kepada organisasi, baik yang bersifat finansial maupun non finansial. Bhatti (2011) menemukan bahwa kesesuaian kompensasi yang diterima karyawan dapat meningkatkan komitmen organisasional. Riana and Wirasedana (2016) menemukan bahwa kompensasi berpengaruh signifikan terhadap komitmen organisasional. Demikian pula, penelitian Rizal et al., (2014) menemukan bahwa kompensasi berpengaruh signifikan terhadap komitmen organisasional. Kompensasi yang dirasakan oleh karyawan berpengaruh positif dan signifikan terhadap komitmen organisasional (Arifin et al., 2016). Pemberian kompensasi yang sesuai dapat menumbuhkan motivasi kerja dan komitmen karyawan terhadap organisasi. Haryani, dkk (2015) menemukan kompensasi finansial dan kompensasi non finansial berpengaruh positif dan signifikan terhadap motivasi, artinya jika kompensasi finansial dan non finansial mengalami peningkatan maka motivasi kerja menjadi semakin meningkat. Selanjutnya Erwansyah, dkk (2015) menjelaskan kompensasi memiliki tingkat signifikansi tinggi terhadap motivasi kerja dengan.

Pemberian kompensasi yang sesuai dengan beban kerja karyawan dapat meningkatkan motivasi kerja. Motivasi kerja merupakan pemberian daya penggerak yang dapat memunculkan kegairahan kerja agar karyawan mau bekerja sama, bekerja efektif, dan terintegrasi dengan segala daya upaya untuk mencapai kepuasan bahkan menjadi alat menuju kinerja terbaik (Hasibuan 2012:95). Negash (2014) menemukan kompensasi berpengaruh positif dan signifikan terhadap motivasi kerja, bahkan kompensasi yang sesuai dapat meningkatkan motivasi kerja dan kinerja (Tufail and Muhammad, 2015). Pemberian motivasi kerja kepada karyawan juga dapat meningkatkan komitmen organisasional. Karyawan yang memiliki komitmen organisasional tinggi selalu menjalin hubungan yang erat antar-karyawan dengan organisasi untuk mewujudkan tujuan organisasi (Robbins and Judge, 2017).

Motivasi kerja berpengaruh terhadap tingkat komitmen seorang karyawan termasuk sejumlah faktor yang menyebabkan karyawan menyalurkan dan mempertahankan tingkah laku dalam suatu tekad tertentu. Penelitian yang dilakukan (Iqbal et al., 2013; Alimohammadi dan Neyshabor, 2013; dan Wardhani et al., 2015) 
menemukan terdapat pengaruh positif dan signifikan antara motivasi kerja terhadap komitmen organisasional. Karyawan yang termotivasi dalam bekerja, cenderung menunjukkan komitmennya terhadap organisasi (Rafique et al., 2014). Motivasi kerja karyawan berpengaruh positif terhadap komitmen organisasional (Brown, 2007). Karyawan yang memiliki motivasi kerja sangat penting bagi kesuksesan organisasi (Schein, 1996) sehingga memahami karyawan dan apa yang memotivasi karyawan dalam bekerja dapat menjadi penggerak dalam menguatkan komitmen organisasi. Penelitian oleh Choong et al. (2011) menyatakan bahwa motivasi kerja berpengaruh signifikan terhadap komitmen organisasional.

Penelitian ini bertujuan untuk; 1). Menganalisis pengaruh kompensasi terhadap komitmen organisasional. 2). Menganalisis pengaruh kompensasi terhadap motivasi kerja. 3) Menganalisis pengaruh motivasi kerja terhadap komitmen organisasional. Dan 4). Menganalisis peran motivasi kerja memediasi pengaruh kompensasi terhadap komitmen organisasional.

\section{TINJAUAN LITERATUR}

\section{Penelitian Terdahulu}

Penelitian yang dilakukan oleh (Yamali, 2018; Bhatti, 2011) menemukan bahwa jika karyawan diberikan kompensasi yang sesuai maka, karyawan tersebut cenderung memiliki komitmen organisasional tinggi. Rizal et al., (2014) menemukan bahwa kompensasi berpengaruh signifikan terhadap komitmen organisasional. Milgo et al., (2014) dalam penelitiannya menemukan hasil kompensasi menunjukan pengaruh signifikan dengan komitmen karyawan. Prabowo, dkk. (2015) menemukan hasil yang sama yaitu kompensasi berpengaruh positif terhadap komitmen organisasional

Engr and Owais (2012) menemukan bahwa komponen kompensasi lebih berpengaruh terhadap motivasi kerja. Demikian pula (Mushawir et al.. 2019; Negash et al., 2014) menemukan bahwa kompensasi berpengaruh positif terhadap motivasi kerja. Tufail dan Muhammad (2015) menemukan bahwa kompensasi yang sesuai dapat meningkatkan motivasi kerja. Sedangkan (Singhvi et al., 2018; Erwansyah, dkk, 2015) menemukan bahwa kompensasi berpengaruh positif dan signifikan terhadap motivasi kerja dengan tingkat signifikansi tinggi.

Aborisade and Emeka (2009) menemukan terdapat hubungan yang signifikan antara motivasi kerja terhadap komitmen organisasional karyawan. Altindis (2011) menemukan bahwa motivasi kerja berkorelasi terhadap komitmen organisasional. Danish et al., (2012) menemukan bahwa motivasi kerja berpengaruh positif terhadap komitmen karyawan di dalam penelitiannya. Iqbal et al., (2013) menemukan bahwa ada hubungan positif dan signifikan antara motivasi kerja terhadap komitmen organisasional.

Rizal et al., (2014) menemukan bahwa kompensasi mempengaruhi komitmen organisasional melalui motivasi kerja. Erwansyah, dkk (2015) menemukan bahwa kompensasi berpengaruh positif dan signifikan terhadap motivasi kerja karena memiliki tingkat signifikansi tinggi. Yudha dan Fatin (2015) menemukan hasil penelitian menunjukkan bahwa motivasi kerja berpengaruh secara positif dan signifikan terhadap komitmen organisasional.

\section{Kompensasi}

Suparyadi (2015:271) menyatakan bahwa kompensasi merupakan keseluruhan imbalan yang diterima oleh karyawan sebagai penghargaan atas kontribusi yang diberikan kepada organisasi, baik yang bersifat finansial maupun non finansial. Hasibuan 
(2012:118) menyatakan bahwa kompensasi adalah semua pendapatan yang berbentuk uang, barang langsung atau tidak langsung yang diterima karyawan sebagai imbalan jasa yang diberikan kepada organisasi. Tingkatan kompensasi yang diterima oleh setiap karyawan tentu berbeda - beda. Tingkatan kompensasi yang diperoleh oleh setiap karyawan menentukan status, gaya hidup, dan perasaan karyawan terhadap organisasi organisasi. Kasenda, (2013), menjelaskan bahwa kompensasi juga dikatakan sebagai semua imbalan yang diterima oleh seorang pekerja atas jasa atau hasil kerjanya pada sebuah organisasi dimana imbalan tersebut dapat berupa uang maupun barang, baik langsung maupun tidak langsung

\section{Motivasi Kerja}

Motivasi kerja adalah pemberian daya penggerak yang menciptakan kegairahan kerja seseorang, agar mereka mau bekerja sama, bekerja efektif dan terintegrasi dengan segala daya upaya untuk mencapai kepuasan bahkan motivasi kerja adalah alat terbaik untuk kinerja terbaik (Hasibuan 2012:95). Menurut Adair (2007:192) motivasi kerja adalah suatu hal yang membuat seseorang mau melakukan sesuatu untuk mencapai tujuan organisasi. Meyer et al. (2004), menyatakan bahwa motivasi kerja adalah sekumpulan kekuatan energi yang berasal baik dari dalam maupun luar individu, untuk memulai perilaku yang berhubungan dengan pekerjaan, sekaligus menentukan bentuk, arah, intensitas, dan jangka waktunya. Oleh karena itu, motivasi kerja dapat dikatakan suatu proses dimana kebutuhan-kebutuhan mendorong seseorang untuk melakukan serangkaian kegiatan yang mengarah pada tercapainya suatu tujuan tertentu (Munandar, 2008:323).

\section{Komitmen Organisasional}

Komitmen organisasional merupakan sikap yang menggambarkan seorang individu atau karyawan terikat pada organisasi (Griffin, 2014:15). Komitmen organisasional terbagi atas tiga aspek yaitu affective commitment, continuance commitment dan normative commitment (Meyer dan Allen, 1993; Ortego-Parra dan Castillo, 2013). Affective commitment umumnya menyatakan karyawan akan tetap tinggal bersama organisasi dikarenakan mereka ingin tinggal (because they want to). Karyawan dengan continuance commitment kuat tetap tinggal bersama organisasi karena harus tinggal bersama organisasi (because they have to). Sementara karyawan dengan normative commitment kuat tetap tinggal bersama organisasi karena merasa memang harus bersama (because they feel that they have to). Robbins dan Judge (2017) menyatakan komitmen organisasional merupakan suatu keadaan karyawan memihak terhadap tujuan organisasi dan ingin tetap mempertahankan keanggotaannya. Sedangkan Luthans (2008:147) menegaskan komitmen organisasional sebagai keinginan kuat seseorang karyawan mempertahankan keanggotaan dalam suatu organisasi.

\section{METODOLOGI}

Penelitian ini merupakan penelitian kausalitas untuk menguji pengaruh antara dua variabel atau lebih. Penelitian ini menguji hipotesis pengaruh kompensasi terhadap komitmen organisasional, pengaruh kompensasi terhadap motivasi kerja, pengaruh motivasi kerja terhadap komitmen organisasional, dan peran motivasi kerja dalam memediasi pengaruh kompensasi terhadap komitmen organisasional. Penelitian dilakukan di PT Jenggala Keramik Bali jalan Uluwatu II, Jimbaran, Kabupaten Badung, Bali sebagai industri keramik terbesar dan terkemuka di Bali. Selain itu terdapat permasalahan komitmen organisasional dan masih sedikit penelitian yang meneliti di 
bidang industri khususnya industri keramik. Populasi penelitian ini adalah seluruh karyawan PT Jenggala Keramik, dengan total 145 orang karyawan. Teknik sampling yang digunakan dalam penelitian ini adalah sampel jenuh menggunakan semua karyawan sebagai sampel kecuali direktur. Namun demikian, dari seluruh kuesioner yang disebarkan jumlah kuesioner yang kembali sebanyak 107 karyawan atau dengan respon partisipasi sebanyak $73,79 \%$.

Pengumpulan data dilakukan dengan penyebaran kuesioner menggunakan skala Likert lima skala yang menggunakan skala ordinal mulai dengan sangat setuju $(\mathrm{SS})=5$. setuju $(\mathrm{S})=4$, netral $(\mathrm{N})=3$, tidak setuju $(\mathrm{TS})=2$, dan sangat tidak setuju $(\mathrm{STS})=1$. Variabel yang diukur dijabarkan menjadi indikator variabel, kemudian indikator tersebut dijadikan sebagai titik tolak untuk menyusun item-item instrumen yang dapat berupa pernyataan. Instrumen penelitian mengacu pada Mayer dan Allen's (1990) untuk komitmen organisasi, kompensasi mengacu pada Hasibuan (2012:86) dan motivasi dielaborasi dari penelitian Ryan dan Deci (2000). Teknik analisis data yang digunakan dalam penelitian ini adalah analisis jalur (Path Analysis). Analisis jalur menggunakan dua persamaan sub struktur sebagai berikut.

Persamaan Sub-struktural 1

$$
\mathrm{M}=\beta_{2} \mathrm{X}+\mathrm{e}_{1}
$$

Persamaan Sub-struktural 2

$$
\mathrm{Y}=\beta_{1} \mathrm{X}+\beta_{3} \mathrm{M}+\mathrm{e}_{2}
$$

Keterangan:

$\mathrm{Y}=$ Komitmen Organisasional

$\mathrm{X}=$ Kompensasi

$\mathrm{M}=$ Motivasi Kerja

$\beta_{1}, \beta_{2}, \beta_{3}=$ Koefisien regresi variabel

$\mathrm{e}=$ Error

\section{HASIL DAN PEMBAHASAN}

Hasil uji validitas terhadap instrumen yang digunakan dalam penelitian disajikan pada Tabel 1 yang menunjukkan bahwa seluruh instrumen pertanyaan variabel komitmen organisasional, kompensasi, dan motivasi kerja memiliki nilai koefisien korelasi yang lebih besar dari angka 0,30 . Hal ini menunjukkan bahwa butir-butir pernyataan dalam instrumen penelitian tersebut telah valid. Demikian pula uji reliabilitas instrumen penelitian menggunakan nilai Alpha Cronbach, yakni untuk mengetahui unidimensionalitas butir-butir pernyataan terhadap variabel laten yang diteliti. Nilai Alpha Cronbach dinyatakan reliabel jika lebih besar atau sama dengan 0,60 dan telah dinyatakan reliabel. Rekapitulasi hasil uji validitas dan reliabilitas instrumen penelitian ditampilkan pada (Tabel 1).

Tabel 1. Hasil Uji Validitas dan Reliabilitas Instrumen

\begin{tabular}{ccccc}
\hline No & Variabel & Item Pertanyaan & $\begin{array}{c}\text { Korelasi Total } \\
\text { Item }\end{array}$ & Keterangan \\
\hline 1 & Kompensasi $(\mathrm{X})$ & $\mathrm{X}_{1}$ & 0,876 & Valid \\
& Alpha Cronbach= 0,892 & $\mathrm{X}_{2}$ & 0,861 & Valid \\
& (reliable) & $\mathrm{X}_{3}$ & 0,827 & Valid \\
& & $\mathrm{X}_{4}$ & 0,793 & Valid \\
\hline
\end{tabular}




\begin{tabular}{|c|c|c|c|c|}
\hline No & Variabel & Item Pertanyaan & $\begin{array}{c}\text { Korelasi Total } \\
\text { Item }\end{array}$ & Keterangan \\
\hline \multirow{3}{*}{2} & \multirow{4}{*}{$\begin{array}{c}\text { Motivasi Kerja (M) } \\
\text { Alpha Cronbach= 0,862 } \\
\text { (reliable) }\end{array}$} & $\mathrm{X}_{5}$ & 0,834 & Valid \\
\hline & & $\mathrm{M}_{1}$ & 0,828 & Valid \\
\hline & & $\mathrm{M}_{2}$ & 0,885 & Valid \\
\hline \multirow{5}{*}{3} & & $\mathrm{M}_{3}$ & 0,881 & Valid \\
\hline & \multirow{4}{*}{$\begin{array}{c}\text { Komitmen Organisasional }(\mathrm{Y}) \\
\text { Alpha Cronbach }=0,860 \\
\text { (reliable) }\end{array}$} & $\mathrm{M}_{4}$ & 0,776 & Valid \\
\hline & & $\mathrm{Y}_{1}$ & 0,870 & Valid \\
\hline & & $\mathrm{Y}_{2}$ & 0,894 & Valid \\
\hline & & $\mathrm{Y}_{3}$ & 0,904 & Valid \\
\hline
\end{tabular}

Sumber: Data diolah, 2019

Hasil perhitungan dengan path analisis persamaan substruktur 1 ditunjukkan pada Tabel 2 berikut.

Tabel 2. Analisis regresi substruktur 1

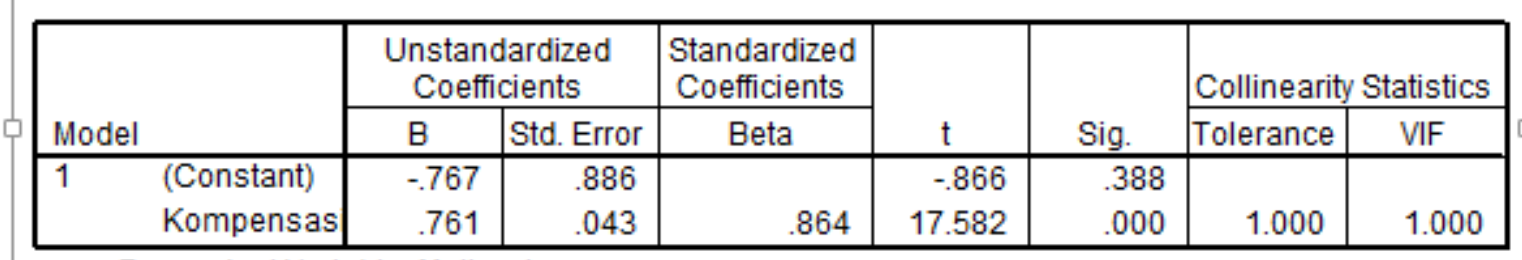

a. Dependent Variable: Motivasi

Selanjutnya perhitungan regresi persamaan substruktur 2 didapat hasil analisis pada Tabel 3 berikut.

Tabel 3. Analisis regresi substruktur 2

\begin{tabular}{|c|c|c|c|c|c|c|c|c|}
\hline \multirow{2}{*}{\multicolumn{2}{|c|}{ Model }} & \multicolumn{2}{|c|}{$\begin{array}{l}\text { Unstandardized } \\
\text { Coefficients }\end{array}$} & \multirow{2}{*}{$\begin{array}{c}\text { Standardized } \\
\text { Coefficients }\end{array}$} & \multirow[b]{2}{*}{$\mathrm{t}$} & \multirow[b]{2}{*}{ Sig. } & \multicolumn{2}{|c|}{ Collinearity Statistics } \\
\hline & & $\mathrm{B}$ & Std. Error & & & & Tolerance & VIF \\
\hline \multirow[t]{3}{*}{1} & (Constant) & -2.022 & .862 & & -2.346 & .021 & & \\
\hline & Kompensasi & .467 & .083 & .598 & 5.601 & .000 & .254 & 3.944 \\
\hline & Motivasi & .234 & .095 & .264 & 2.477 & .015 & .254 & 3.944 \\
\hline
\end{tabular}

a. Dependent Variable: Komitmen org.

Perhitungan koefisien path dilakukan dengan analisis regresi melalui software (SPSS) 17.0 for Windows diperoleh dari hasil sebagai berikut.

Hasil Analisis Jalur Persamaan Regresi 1

$$
\begin{aligned}
& \mathrm{S}(\beta)=(0,043) \\
& \mathrm{t} \quad=(17,582) \\
& \mathrm{R}^{2} \quad=0,746 \quad \mathrm{df}=105 \quad \mathrm{~F}=309,119 \mathrm{Sig}=0,000 \\
& M=0,864 \mathrm{X}+0,254
\end{aligned}
$$

Hasil Analisis Jalur Persamaan Regresi 2

$$
\begin{aligned}
& \mathrm{S}(\beta)=0,083 \quad 0,095 \\
& \mathrm{t} \quad=5,601 \quad 2,477 \\
& \mathrm{R}^{2}=0,700 \quad \mathrm{df}=104 \quad \mathrm{~F}=121,225 \quad \mathrm{Sig}=0,000 \\
& \mathrm{Y}=0,598 \mathrm{X}+0,264 \mathrm{M}+0,3
\end{aligned}
$$


Berdasarkan model substruktur 1 dan substruktur 2, maka dapat disusun model diagram jalur akhir. Sebelum menyusun model diagram jalur akhir, terlebih dahulu dihitung nilai standar eror sebagai berikut.

$$
\begin{aligned}
& \mathrm{e}=\sqrt{1-R 1^{2}} \\
& \mathrm{e}_{1}=\sqrt{1-R 1^{2}}=\sqrt{1-0,746}=0,254 \\
& \mathrm{e}_{2}=\sqrt{1-R 2^{2}}=\sqrt{1-0,700}=0,3
\end{aligned}
$$

Berdasarkan perhitungan pengaruh error (e), didapatkan hasil pengaruh error $\left(\mathrm{e}_{1}\right)$ sebesar 0,254 dan pengaruh $\left(\mathrm{e}_{2}\right)$ sebesar 0,3

Hasil koefisien determinasi total adalah sebagai berikut.

$$
\mathrm{R}^{2} \mathrm{~m}=1-\left(\mathrm{Pe}_{1}\right)^{2}\left(\mathrm{Pe}_{2}\right)^{2}
$$

$$
=1-(0,254)^{2}(0,3)^{2}=1-(0,064)(0,09)=1-0,005=0,994
$$

Nilai determinasi total sebesar 0,994 mempunyai arti bahwa sebesar 99,4 persen variasi komitmen organisasional dipengaruhi oleh kompensasi dan motivasi kerja, sedangkan sisanya sebesar 0,06 persen dijelaskan oleh faktor lain di luar model. Selanjutnya hasil koefisien jalur pada hipotesis penelitian dapat digambarkan pada Gambar 1 berikut. Berdasarkan diagram jalur pada Gambar 1, maka dapat dihitung besarnya pengaruh langsung dan pengaruh tidak langsung serta pengaruh total antar variabel.

\begin{tabular}{|c|c|c|c|}
\hline $\begin{array}{l}\text { Pengaruh } \\
\text { Variabel }\end{array}$ & $\begin{array}{l}\text { Pengaruh } \\
\text { Langsung }\end{array}$ & 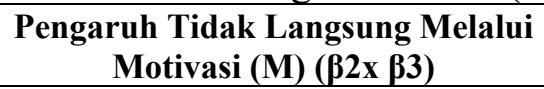 & Pengaruh Total \\
\hline $\mathrm{X} \rightarrow \mathrm{M}$ & 0,864 & & 0,864 \\
\hline $\mathrm{M} \rightarrow \mathrm{Y}$ & 0,264 & & 0,264 \\
\hline$X \rightarrow Y$ & 0,598 & 0,228 & 0,826 \\
\hline
\end{tabular}

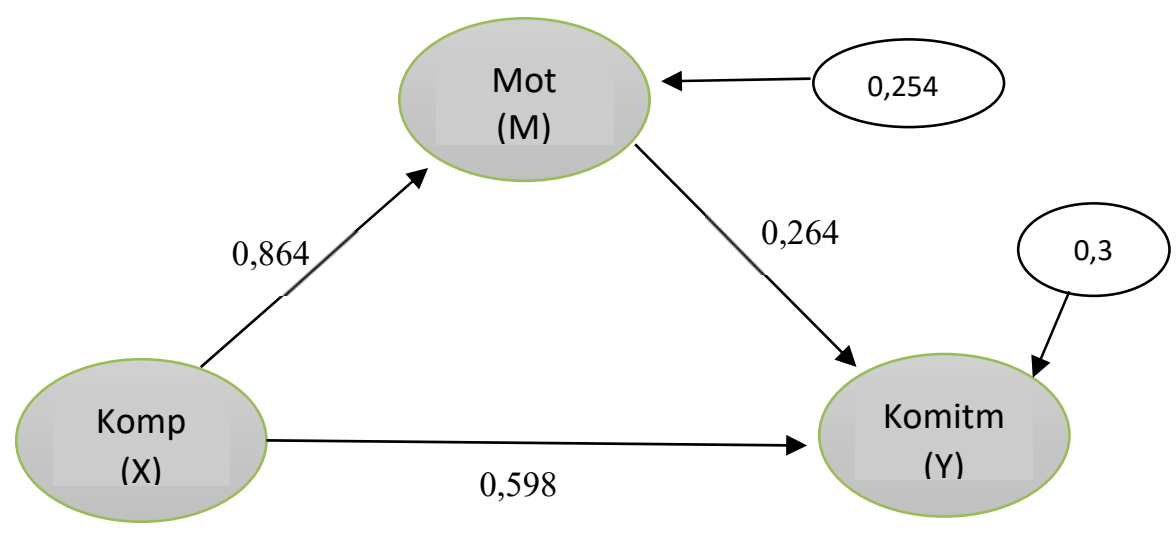

Perhitungan pengaruh antar variabel dirangkum dalam Tabel 5. sebagai berikut.

Tabel 4. Pengaruh Langsung, Pengaruh Tidak Langsung dan Pengaruh Total Kompensasi (X), Motivasi Kerja (M), dan Komitmen Organisasional (Y)

Sumber: Data diolah, 2019

Uji Sobel dihitung dengan rumus dibawah ini:

$$
\mathrm{Z}=\frac{a b}{\sqrt{a^{2} S b^{2}+b^{2} S a^{2}+S a^{2} S b^{2}}}
$$


Keterangan:

$$
\begin{aligned}
\mathrm{a} & =0,864 \\
\mathrm{Sa} & =0,043 \\
\mathrm{~b} & =0,264 \\
\mathrm{Sb} & =0,095 \\
\mathrm{z} & =\frac{0,864 \times 0,264}{\sqrt{0,864^{2} 0,095^{2}+0,264^{2} 0,043^{2}+0,043^{2} 0,095^{2}}} \\
\mathrm{z} & =\frac{0,2281}{\sqrt{0,0067+0,0001+0,0000}} \\
\mathrm{z} & =2,7494
\end{aligned}
$$

Berdasarkan hasil uji sobel dalam penelitian ini menunjukkan bahwa hasil tabulasi $\mathrm{z}=2,7494>1,96$ yang berarti variabel mediasi yakni motivasi kerja dinilai secara signifikan memediasi pengaruh kompensasi terhadap komitmen organisasional.

\section{PEMBAHASAN}

Hipotesis satu (H1) pada penelitian ini menyatakan bahwa kompensasi berpengaruh positif dan signifikan terhadap komitmen organisasional. Hasil uji hipotesis menunjukan bahwa kompensasi memiliki pengaruh positif dengan nilai koefisien jalur (ß) sebesar 0,598 dan tingkat signifikan 0,000 lebih kecil dari 0,05. Nilai positif dari koefisien regresi variabel kompensasi meningkat, maka komitmen organisasional juga meningkat dan memiliki pengaruh positif. Hasil penelitian ini mendukung temuan Bhatti (2011) menemukan bahwa jika karyawan diberikan kompensasi yang sesuai maka karyawan tersebut akan memiliki komitmen organisasional yang tinggi. Riana and Wirasedana (2016) menemukan bahwa kompensasi yang diterima oleh karyawan berdampak signifikan dalam meningkatkan komitmen organisasional.

Hipotesis dua (H2) pada penelitian ini menyatakan bahwa kompensasi berpengaruh positif dan signifikan terhadap motivasi kerja. Hasil uji hipotesis menunjukkan bahwa kompensasi berpengaruh positif dengan nilai koefisien jalur (B) sebesar 0,864 dan tingkat signifikan 0,000 lebih kecil dari 0,05. Nilai positif dari koefisien regresi mengindikasikan bahwa ketika kompensasi yang dirasakan telah sesuai, maka motivasi kerja karyawan cenderung semakin meningkat. Hasil penelitian ini mendukung temuan penelitian yang dilakukan Engr dan Owais (2012) bahwa komponen kompensasi yang lebih baik dapat meningkatkan motivasi kerja karyawan. Selanjutnya Negash et al., (2014) menemukan bahwa kompensasi yang dirasakan sesuai oleh karyawan mampu meningkatkan motivasi kerja. Dengan kata lain, ketika balas jasa (kompensasi) yang diberikan cukup memadai, karyawan cenderung lebih mudah untuk termotivasi (Wolor et al., 2019). Motivasi merupakan proses yang berperan pada intensitas, arah, dalam upaya individu ke arah pencapaian sasaran (Robbins dan Judge, 2017). Karyawan menganggap kompensasi yang diberikan oleh perusahaan sesuai dengan harapan, maka motivasi kerja karyawan menjadi semakin meningkat (Mushawir et al.. 2019).

Hipotesis tiga (H3) menyatakan bahwa motivasi berpengaruh positif dan signifikan terhadap komitmen organisasional. Hasil Analisis uji hipotesis menunjukkan bahwa motivasi kerja memiliki pengaruh positif dengan nilai koefisien jalur (ß) sebesar 0,264 dan tingkat signifikan 0,015 lebih kecil dari 0,05 . Nilai positif koefisien regresi menginformasikan bahwa meningkatnya motivasi kerja dapat meningkatkan komitmen karyawan terhadap organisasi. Hasil penelitian ini mendukung temuan Iqbal et al., (2013) 
bahwa terdapat hubungan positif dan signifikan antara motivasi kerja dengan komitmen organisasional. Dengan kata lain, karyawan yang memiliki motivasi tinggi dalam bekerja cenderung lebih mudah dan lebih berkomitmen terhadap organisasi. Rahmawati dan norhasni (2015) menyatakan bahwa semakin tinggi motivasi kerja karyawan, maka karyawan menjadi semakin berkomitmen terhadap organisasi.

Hipotesis empat (H4) terkait dengan peran motivasi kerja memediasi pengaruh kompensasi terhadap komitmen organisasional dengan membuktikan peran motivasi kerja memediasi secara signifikan. Hasil uji mediasi menggunakan Sobel test peran motivasi kerja pada pengaruh kompensasi terhadap komitmen organisasional dengan hasil $\mathrm{z}=2,7494>1,96$. Berarti hipotesis keempat $\left(\mathrm{H}_{4}\right)$ adalah signifikan. Temuan penelitian ini mendukung hasil penelitian dari Rizal et al (2014) bahwa motivasi kerja secara signifikan memediasi pengaruh kompensasi terhadap komitmen organisasional. Temuan tersebut juga menginformasikan bahwa kompensasi berpengaruh langsung terhadap komitmen organisasional dan berpengaruh tidak langsung terhadap komitmen organisasional melalui motivasi kerja.

\section{KESIMPULAN}

Komitmen organisasional merupakan suatu keterikatan antara karyawan dengan organisasi. Keterikatan tersebut dianggap sebagai respon emosional ketika karyawan percaya pada tujuan organisasi sehingga menunjukkan keinginan yang kuat untuk mempertahankan keanggotaan dalam organisasi. Dua aspek penting yang mampu meningkatkan komitmen organisasional adalah kompensasi dan motivasi kerja. Temuan penelitian ini menginformasikan bahwa semakin sesuai kompensasi yang dirasakan oleh karyawan, maka komitmen karyawan terhadap organisasi cenderung semakin meningkat. Kompensasi yang dirasakan telah sesuai bahkan dapat memicu munculnya motivasi kerja. Disamping itu, karyawan yang merasakan kompensasi yang diterima telah sesuai dengan harapan dapat semakin meningkatkan motivasi kerja. Karyawan dengan motivasi kerja tinggi cenderung lebih berkomitmen terhadap organisasi. Penelitian ini juga menginformasikan bahwa semakin tinggi motivasi kerja karyawan, maka semakin kuat komitmen karyawan terhadap organisasi. Selanjutnya, temuan penelitian ini menginformasikan bahwa motivasi kerja mampu memediasi pengaruh kompensasi terhadap komitmen organisasional. Hasil ini mengindikasikan bahwa kompensasi secara langsung mampu meningkatkan komitmen karyawan terhadap organisasi dan secara tidak langsung meningkatkan komitmen organisasional melalui motivasi kerja.

Penelitian ini memiliki keterbatasan terkait dengan pengumpulan data menggunakan persepsi karyawan yang dapat berubah setiap saat. Demikian pula penelitian ini hanya dilakukan pada satu perusahaan sehingga generalisasi temuan yang dihasilkan masih perlu diuji kembali pada perusahaan lain atau industri yang berbeda.

\section{REFERENSI}

Aborisade, R., Emeka E. O. (2009). "The Role of Motivation in Enhancing Job Commitment in Nigeria Industries: A Case Study of Energy Foods Company Limited, Ibadan”. Kamla-Raj J Soc Sci, 19(2): 149-154 
Adair, J. (2007). Pemimpin yang berpusat Pada Tindakan. Binarupa Aksara: Jakarta.

Alimohammadi, M., Neyshabor, A. J. (2013). Work motivation and organizational commitment among Iranian employees. International Journals Of Research in Organizational Behaviour and Human Resource Management, Vol. 1, No.3, pp. $1-12$.

Altindis, S. (2011). Job Motivation And Organizational Commitment Among The Health Professionals: A Questionnaire Survey. African Journal of Business Management. Vol. 5(21), pp. 8601-8609.

Arifin, M. Z., Alhabsji, T., Utami, H. N. (2016). Pengaruh Beban Kerja Dan Kompensasi Terhadap Komitmen Organisasional Dalam Upaya Meningkatkan Kinerja Karyawan. Jurnal Bisnis dan Manajemen.Vol. 3 No.2.

Bhatti, K.K. (2011). "Influence of Employee Compensation on Organizational Commitment and Job Satisfaction: A Case Study of Educational Sector of Pakistan". Vol. 2 No. 8; May 2011. 25-32

Brown, D., Marcel A. S. 2007. Job Satisfaction, organizational commitment, and religious commitment of full-time university employees. Journal of Research on Christian Education, Vol. 16, No. 2, pp. 211-241.

Choong, Y.O., Wong, K.L., and Lau, T.C. (2011). Intrinsic motivation and organizational commitment in the Malaysian private higher education institutions: An empirical study. International Refereed Research Journal, Vol. 2, No. 4, 40-50.

Danish, R. Q., Rehmanand, S,U, Munir, Y. (2012). The Impact of Motivation on Employees Commitment: Evidence from Public and Private Sector of Pakistan. World Review of Business Research; Vol. 2. No. 1.

Engr, W. K., Owais, M. (2012). Effect of Compensation on Motivating Employees in Public and Private Banks of Peshawar (BOK and UBL). Journal of Basic and Applied Scientific Research.V 2(5)4616-4623

Griffin, R.W. (2014). "Management, $7^{\text {th }}$ edition". Massachusetts: Houghton Mifflin Company.

Haryani, Sukma, S., Hamid, J., Susilo, H. (2015). Pengaruh Kompensasi Terhadap Motivasi Kerja Dan Kinerja (Studi Pada Karyawan Pt. Telekomunikasi Indonesia, Tbk Malang). Jurnal Administrasi Bisnis (JAB). Vol. 25 No. 1

Hasibuan, M. S. P. (2012). Manajemen Sumber Daya Manusia. Edisi Revisi, Jakarta: Penerbit Bumi Aksara

Iqbal, N., Ahmad, N., Majid, M., Nadeem, M., Javed, K., Zahra, A., Ateeq, M. (2013). "Role of employee motivational employee's commitment in the context of banking sector of D.G.KHAN, Pakistan". Journal of Human Resource Management. Vol 1(1): 1-8

Kasenda, R. (2013). Kompensasi dan motivasi pengaruhnya terhadap kinerja karyawan pada PT. Bangun Wenang Beverages Company Manado. Jurnal EMBA: Jurnal Riset Ekonomi, Manajemen, Bisnis dan Akuntansi, 1(3).

Luthans, F. (2008). Organizational behavior. United States: McGraw-Hill. 
Meyer, J. P., Allen, N. J., and Smith, C. A. (1993). Commitment to organizations and occupations: Extension and test of a three-component conceptualization. Journal of Applied Psychology, Vol. 78, pp. 538-551.

Meyer, J. P., Becker, T. E., and Vandenberghe, C. (2004). Employee commitment and motivation: A conceptual analysis and integrative model. Journal of Applied Psychology, Vol. 89, No. 6. pp. 991-1007.

Munandar, A.S. (2008). Psikologi industri dan organisasi. Jakarta: Universitas Indonesia.

Mogotsi, I.C., Boon, J.A., and Fletcher, L. (2011). Modelling the relationships between knowledge sharing, organisational citizenship, job satisfaction and organisational commitment among school teachers in Botswana. African Journal of Library, Archives and Information Science, Vol. 21, No. 1, pp. 41-58.

Milgo, A. C., Namusonge, G., Kanali, C., Makokha, E. N. (2014). Reward and Compensation as a Determinant of Employee Commitment: A Survey of Ktda Tea Factories in Kenya. European Journal of Business and Management. Vol.6, No.15, 2014

Mushawir, A. J. A. A., Muis, M., \& Umar, F. (2019). The Effect of Financial and NonFinancial Compensation on Work Motivation and Officials' Performance at Hasanuddin University, Makassar. Hasanuddin Journal Of Business Strategy, 1(2), 14-24.

Negash, R., Zewude., Megersa, R. (2014).”The Effect of Compensation on Employees Motivation: In Jimma University Academic Staff'. Basic Research Journal of Business Management and Accounts ISSN 2315-6899. Vol. 3(2) pp. 17-27

Prabowo, A., Alamsyah, A., Noermijati. (2015). Pengaruh Kompensasi dan Kepuasan Kerja terhadap Komitmen Organisasional Perawat dan Bidan Kontrak di RS Bhayangkara Hasta Brata Batu Malang. Jurnal Aplikasi Manajemen (JAM). Vol 14 No 1.

Rafique, A., Tayyab, M.S.B., Kamran, M., and Ahmed.M.N. (2014). A study of the factors determining motivational level of employees working in public sector of Bahawalpur (Punjab, Pakistan). International Journal of Human Resource Studies, Vol. 4, No. 3, pp. 19-34

Rahmawati, Y., Norhasni, Z., A. (2015). Relationship Between Motivation and Organizational Commitment among Scout Volunteers in East Kalimantan. Journal of Social Science Studies. Vol. 2, No. 1

Riana, I G., Wirasedana, I. W. P. (2016). The Effect of Compensation on Organisational Commitment and Employee Performance with the Labour Union as the Moderating Variable. Social and Economic Science. Vol. 3 (2016) No. 2

Rizal, M., Idrus, M. S., Djumahir, Mintarti, R. (2014). "Effect of Compensation on Motivation, Organizational Commitment and Employee Performance (Studies at Local Revenue Management in Kendari City)".International Journal of Business and Management Invention. Vol 3, Issue 2, pp. 64-79 
Ryan, R.M., Deci, E.L. (2000). Self-Determination Theory and the facilitation of intrinsic motivation, social development, and well-being. American Psychologist, Vol. 55, No. 1, pp. 68-78.

Robbins, S., Judge, T. A. (2017). Perilaku Organisasi. Jakarta: Salemba Empat.

Schein, E. 1996 . Culture: The Missing Concept in Organization Studies. Administrative Science Quarterly, Vol. 41, No. 2, pp. 229 - 41.

Suparyadi, H. (2015). Manajemen Sumber Daya Manusia-Menciptakan Keunggulan Bersaing Berbasis Kompetensi SDM Edisi 1. Yogyakarta: Andi

Singhvi, A. S., Dhage, N. N., \& Sharma, P. P. (2018). Compensation and Its Impact on Motivation Employee $\mathrm{s}$ Satisfaction and Employee $\mathrm{S}$ Performance. International Academic Journal of Organizational Behavior and Human Resource Management, 5(2), 1-43.

Testa, M. R., (2001). Organizational commitment, job satisfaction, and effort in the service environment. The Journal of Psychology, Vol. 135, No. 2, pp. 226-236.

Tufail, S., Muhammad S. (2015). "An Empirical Study of Relationship between Compensation, Working Environment and Motivation of Employees in Banking Sector of Pakistan". Journal of Marketing and Consumer Research, An International Peer-reviewed Journal. Vol.6, 2015

Wardhani, Winda Kusuma; Heru Susilo dan Mohammad Iqbal. (2015). Pengaruh Motivasi Kerja Karyawan Terhadap Komitmen Organisasional Dengan Kepuasan Kerja Sebagai Variabel Intervening. Jurnal Administrasi Bisnis(JAB). Vol. 2 No. 1.

Wolor, C. W., Supriyati, Y., \& Purwana, D. (2019). Investigating The Link Between Conflict Management, Compensation, Work Motivation On Employee Performance Sales People. In Journal of International Conference Proceedings (Vol. 2, No. 1).

Yamali, F. R. (2018). Effect of Compensation, Competencies and Organizational Culture on Organizational Commitment its Implications On Experts Performance of Construction Services Company in Jambi Province. IJAME.

Yudha, E. P., Fatin, F., H. (2015). Pengaruh Motivasi Terhadap Komitmen Organisasional Pada Guru Madrasah Ibtidaiyah Islamiyah Kota Madiun. JESTT. Vol. 1 No. 5.

Zayas-Ortiz, M., Rosario, E., Marquez, E., and Gruñeiro, P.C. (2015). Relationship between organizational commitments and organizational citizenship behaviour in a sample of private banking employees. International Journal of Sociology and Social Policy, Vol. 35, No. 1/2, pp. 91-106. 